Sectio capitis. $-\mathbf{A}$ slight scar was visible in the skin, alittle above the right superciliary ridge. This was stated by the atten. dants to be the mark of the wound received by the bursting of the gun. Corresponding with this, and immediately above the right frontal sinus, a piece of the frontal bone was found fractured: the portion was irregular in shape, and nearly the size of a sixpence. It had suffered little displacement. Its edges were quile smooth, as were those of the surrounding bone, but no attempt at union could be perceived. A spicula, balf an inch in length, evidently a piece of the internal table, protruded from the fractured portion horizontally in to the brain, or rather into an excavation of the organ, about the size of a blackbird's egg. This cavity was lined with a yellow granular deposit, tough, and of a semi-cartilaginous consistence. Three or four spicula, of smaller size, and of new formation, were observed shooting from the inner table, around the fractured part. The dura mater terminated abruptly at the edges of the excavation. There was a copious effusion of lymph under the arachnoid of the right hemisphere; bloody serum in the ventricles; and an erosion at the under part of the left anterior lobe, lying on the ala minor of the sphenoid bone, about half an inch in length and a quarter in breadth; its base was tough and membranous.

This case is an additional iustance to those already on record, illustrating the amount of injury and disorganisation which the brain will sometimes sulfer withont life being destroyed, or its peculiar functions being permanently interrupted. In ordinary cases of fracture with depression, it frequently acquires a capability of accommodating itself to the change in the shape and size of the skull which such injury produces. In the present instance, this peculiar tolerance is especially remarkable; as there can be no doubt that the dura mater and brain were lacerated so long back as the period of the accident; and by the pro. truding spicula a constant source of irritation must have been kept up, which ended ultimately in the total destruction of that portion of the organ in its immediate locality. The want of union in the fractured part, although in nearly direct opposition, is also a circumstance worthy of notice.

\section{ON A PECULIAR DEFORMITY OF THE CHEST IN INFANTS.}

\section{To the Edilor of The Lancet.}

SIr:-Perceiring, in the last Number of The Lancet, the report of a paper, read by Mr. Snow before the Westminster Medical Society, on "a peculiar deformity of the chest and spine in children," which, I find, is the same I had previously pointed out in the "Medical Gazette," Jan. 12, 1839; of which I presented an example before the Loudon Medical Society on Feb. 12, 1839, and which was noticed in No. 24 of $\mathrm{THE}_{\mathrm{HE}}$ LANCET of that year, under the head, "Peculiar deformity of the chest in infants;" I shall feel obliged if you will allow me to re. peat, through the pages of your extensively. circulated Journal, my conviction that such deformity is dependent upon a morbid con. dition of the lungs.

That the deformity mentioned in $\mathrm{Mr}$. Snow's paper is the same as I had noticed in mine, I gather from the similarity of the sell. tences describing it, which, considering that Mr. Snow had not, of course, read my paper, since he did not refer to it, is somewhat singular. Thas, Mr. Snow says, "The chest became depressed laterally, the sternum projected forwards, and a channel was left down each side of the thorax, where the cartilages united to the osseous portions of the ribs." I had stated before, "The deformity consists in a depression existing at the line of union between the ribs and their cartilages, in consequence of which the arched form of the front of the thorax is lost, and a channeled appearance, external to the sternum on each side, produced."

Again, Mr. Snow says, "And the sides of the chest were pressed further in during in. spiration, and returned again during expira. tion; thus the motion of the ribs became the reverse of the natural one." I had before written, "At the moment of inspiration, they (the ribs) being forced in wards instead of drawn outwards, and thus the size of the thorax transversely diminishing, instead of being augmented." No doubt, therefore, can be entertained, that the cases alluded to by Mr. Snow and by myself are the same.

There are several reasons why I cannot agree with that gentleman as to the cause of such deformity being ealargement of the abdomen. Firstly, Because $I$ have seen cases where there has been very inconsiderable enlargement of the abdomen; and where, nevertheless, the deformity has been very distinct.

Indly. I see infants and young children with the abdomen much enlarged, where no such deformity exists; and, therefore, cannot think "the degree of deformity is al wass in proportion to the enlargement."

3rdly. The altered movement of the ribs in respiration is very common in the course of $d$ iseases of the lungs in children, without any tumidity of the abdomen, or any defor. mity of the chest.

Neither can I agrce with Dr. Chowne and Mr. Chance, that it is a scrofulous affection. Rickety or strumous malformation of the chest, which is very common in children, is shown by lateral contraction, as in other cases of rickets the bones themselves are distorted; and hence the alteration of form 
takes place near the centre of the ribs, and not unfrequently is popularly attributed to compression of the infant by holding it under the arms in improper nursing. Such rickety change of form may be combined with disease of the lungs, and then the altered movements of the ribs will be present as well. Such cases have been mentioned ly my brother years ago, in a popular work he wrote at that time.

From the first $I$ imagined, and still am of opinion, that the altered movement of the ribs during respiration arises from disease of the lungs, rendering them solid, and unable to expand at the moment of inspiration; and, $I$ believe further, that the deformity is produced by the continuation of such diseased state of the lungs resulting in atrophy, to a greater cr less degree, of these organs.

That the altered movement of the ribs is in nomeasure dependent upon the altered shape of the chest, but upon the state of the lungs, may be ascertained by any one who has the opportunity of watching the first efforts at respiration made by the infant born in a state of asphyxia. During the first two or three contractions of the diaphragm, until the lungs are duly flled with air, this abnormal inovement of the ribs is perceptible to a remarkable exteat, and is no longer observable when these organs are fully ex. panded. In some instances, indeed, in these infants, though revived, the lungs remain partially solid fur weeks or months after birth; a fact first mentioned by Professor Juerg, of Berlin; and, in these cases, I believe the altered movement of the ribs will continue as well, and prove a constant diagnostic symptom.

But this inversed action of the ribs in inspiration is by no means uncommon in infants attacked with inflammation of the lungs after birth; nay, 1 feel persuaded, in cases of acute broncho-pneumonia, or in cases of pneumonia attacking both lungs, it is seldom absent, and should be looked for and regarded as a symptom in forming an opinion on the case.

Moreover, in obstruction of the primary air-passages, when suficient to hinder a full expansion of the lungs, the same altered movement of the ribs is often, if not always, present. Thus it is perceptible in the later stages of croup; and, I apprehend, is alluded to by $\mathbf{D}$. C Copland (when describing that disease), as "a drawing upwards and inwards of the epigastrinm;" and 1 have generally found it in those in. stances of tubercular enlargement of the bronchial glands, so ably described by $\mathrm{Dr}$. Clark in his work on pulmonary consumption.

The cause of this altered movement is attributed, both by Mr. Suow and by myself, to the action of the diaphragm; which, as Mr. Snow had, of course, not read my paper, renders it probable that the refer- ence is right. His words are, "the action" of the diaphragm, which pressed down the abdomen, and at the same time drew up the cartilages of the lower ribs during each inspiration, made roon for more air than the lungs were inclined to receive." My explanation is," When the diaphragm contracts in inspiration, either one of two things must occur-either the descent of the muscle must bear an exact relation with the limited expansion of the lung, or the space which rvould result from its descent, the lung not expanding, must be filled by a temporary contraction of the walls of the chest, and hence the altered movement of the ribs."

My belief that the deformity of the chest is the consequence of disease of the lungs, mainly resulting from observations in the examinations I have made, I can only offer my post-mortem experience in opposition to Mr. Snow's. That gentleman states, "the lungs were healthy in all the cases except one;" which is not very satisfactory, since he previously meutions he had only in two cases the opportunity to make an examination. It was mentioned, in my first paper, that $I$ had met with and examined four cases, in all of which the lungs were more or less affected; and since then $I$ have opened several children with the same deformity, and have invariably found the lungs diseased.

Another reason why I shonld be led to differ from Mr. Snow is, the unsatisfactory way in which he accounts for the enlargement of the abdomen of which he speaks. In the cases he examined no mesenteric dis. ease was present; nor is there mention of other structural change made, but "the enlargement depended chiefly on elongation and distension of the colon." Elongation ! why, how often, in the dissecting-room, is an appendage to the colon found present, between the sigmoid flexure and rectum, of a foot in length, and yet no alteration in the shape of the thorax visible! And I am at a loss to imagrine a distension so considerable and so constant in the infant, as to effect a change of structure so great as that under consideration.

"The sudden stoppage at the throat to the further access of air," mentioned by Mr. Snow, is a very common, but not a constant symptom; for, in the worst cases, it is absent sometimes. In other words, these infants are usually the subjects of laryngismus stridulus: an affection, the paroxysms of which, when it is not caused by disease at the base of the brain, I believe are owing to a momentary loss of equilibrium between the effort at inspiration and the capacity of the lung to receive air; and on which point I interd to enlarge bereafter, if you will allow me again to trespass on your pages. I cannot think that this sudden stoppage " is a voluntary or instinctive effort;" for $I$ have known it prove, in seve. 
ral cases, instantly fatal; neither do $I$ believe it results from approximation of the posterior palatine arches, and the pressure of the root of the tongue at the same time arainst the palate. I consider it is a spasmodic closure of the glottis, as in other instances of laryngismus stridulus, effected, probably, as suprosed by the late Dr. Hugh Ley, by excitation of the recurrent nerve.

With every apology for taking up so much of the valuable space of your Journal, I am, Sir, your obedient servant,

George A. Rees, M. R. C. S.

5, Artillery place, City-road, March 22, 1841.

\section{VERATRINE.}

WOOD-ANEMONE, OR WILD WIND FLOWER; A SUBSTITUTE FOR SABADILLA, OR VERATRINE.

\section{To the Editor of The Lancet.}

SIR :-As the wild wind fower or woodanemone, which is too commonly known to need description, will appear in the woods next month, I wish to make a suggestion which may save expense to some of the profession and their patients, aud which $I$ have discovered in the course of compiling a new medical herbal, and pursuing some years' study of medical botany; a pursuit of great use and profit to the eclectic physician, who is desirous of success in diseases of very difficult cure.

It appears to me that certain preparations of anemone would supersede the very expensive preparations of the tincture and extract of sabadilla and veratrive, which are now used by one of my early preceptors, Mr. Liston, and others, as external irritants and watery purges in amaurosis and eye-cases. It is worth trying in dropsies, and, perhaps, in deafness. We have no experience of the use of the anemone, but it is much used on the continent. In consequence of English country practice being a common routine of one method in all diseases, the resources of medical botany are scandalously neglected. I have made trial, but not a fair trial of it in a case of amaurosis, in Mr. Woudruff, of Chepstow. The officinal preparations of the wood-anemone (anemóne nemorósa) are a wa. tery and alcoholic ex tract. These are made by several nations on the continent : they make a powder of seven to fifteen grains with one drachm of white sugar, of which the doze is twenty grains, gradually increased to three drachms daily; they also add sixteen grains to 3 iss of wild valerian : divide into eighteen powders, and give one powder daily in water, increasing gradually, in gutta serena and amanrosis. The infusion of meadow anemone is made by putting from one to four drachms of the roots into one pint of boiling water, adding $\xi_{j}$ of sugar; dose $\xi_{i i j}$ or $i v$ three times a-day. The distilled water is also made, and given from two drachms to Zss twice a.day.

$I$ have greatly reinforced my resources in the treatment of long-standing, knotty, and difficult cases, by my last five years' acqui. sitions in the knowledge of medical botany and herbs; gained partly by books, but more particularly by communication with the Anglo.Welch people; it is to the people and their accidental discoveries, and never in this world to the regular profession, that we are indebted for the knowledge of every valuable remedy that bas been discovered. What have ever been the conduct and the bearing of the profession towards all disco. verers and discoveries, the trumpet of bad notoriety has loudly proclaimed!

It is extraordinary to know, by personal observation, the great success of Anglo. Welch and Welch village doctors, and what are called quacks, after the failure of the common routinists in dropsies, scrofula, and various cases in which the common routine is worse than useless. Having been re. gular case-taker for thirteen years, I was glad to see a capital paper in THE LANCET on case-taking. Moreover, was this more general, as you well observe, "the SAN. grados and Pargons could exist no longer in aature, and would only survive in the im. mortal ridicule of Le Sage and Molière."(LANCET, Jan. 30.) Yours ever,

Ross, March 19, 1841 . JOH N FOSBROKE, M.D.

\section{TREATMENT OF PRURITUS ANI.}

\section{To the Editor of THE LANCET.}

Sir :-A correspondent inquires, through your excellent Periodical, the best method of curing pruritus ani. It has already been replied to, but, I am fearful, in part unsatisfactorily; nor do I see how it could be otherwise, as it will be found to proceed from various causes, locally and constitutionally. In proof of which, on referring to my notes upon the subject, I find the three first cases of simple pruritus recorded are totally different.

In the first, the cause of the pruritus proceeded from two slight ulcers. Ointments and lotions had been recommended; no examination being previously made; satisfed by knowing there was an "itching." Here, $I$ helieve, the solid nitrate of silver, from experience, is the very best remedy ; applied, by simply touching the ulcers with the blunt extremity of the caustic, every alternate morning. It occasionally causes some pain; but it is quickly followed by a coolness of the part, and a great diminution, if not a total subsidence, of the itching for that day; and, finally, effects a complete cure. The length of time depends much on the habits and constitution of the patient. 